\title{
Characterizing the effects of elevated temperature on the air void pore structure of advanced gas-cooled reactor pressure vessel concrete using $x$-ray computed tomography
}

\author{
R.C. Stein ${ }^{1,2, a}$, M. Petkovski ${ }^{2}$, D.L. Engelberg ${ }^{3}$, F. Leonard ${ }^{4}$ and P.J. Withers ${ }^{4}$ \\ ${ }^{1}$ Nuclear FiRST Doctoral Training Centre, Universities of Sheffield \& Manchester, UK \\ ${ }^{2}$ Department of Civil and Structural Engineering, University of Sheffield, UK \\ ${ }^{3}$ Research Centre for Radwaste and Decommissioning, University of Manchester, UK \\ ${ }^{4}$ Manchester X-ray Imaging Facility, University of Manchester, UK
}

\begin{abstract}
X-ray computed tomography (X-ray CT) has been applied to nondestructively characterise changes in the microstructure of a concrete used in the pressure vessel structure of Advanced Gas-cooled Reactors (AGR) in the UK. Concrete specimens were conditioned at temperatures of $105{ }^{\circ} \mathrm{C}$ and $250{ }^{\circ} \mathrm{C}$, to simulate the maximum thermal load expected to occur during a loss of coolant accident (LOCA). Following thermal treatment, these specimens along with an unconditioned control sample were characterised using micro-focus X-ray CT with a spatial resolution of 14.6 microns. The results indicate that the air void pore structure of the specimens experienced significant volume changes as a result of the increasing temperature. The increase in the porous volume was more prevalent at $250{ }^{\circ} \mathrm{C}$. Alterations in air void size distributions were characterized with respect to the unconditioned control specimen. These findings appear to correlate with changes in the uni-axial compressive strength of the conditioned concrete.
\end{abstract}

\section{Introduction}

Advanced gas-cooled reactor (AGR) pressure vessels are constructed from high-strength ordinary Portland cement (OPC) - pulverised fuel ash (PFA) concrete. This material is subjected to temperatures of up to $87{ }^{\circ} \mathrm{C}$ during normal plant operation and must withstand temperatures of $250{ }^{\circ} \mathrm{C}$ during a LOCA [1]. Existing research provides contradictory evidence on the effects of elevated temperatures on the microstructure and mechanical properties of OPC - PFA concrete. Nasser and Marzouk [2] reported that after 6 months exposure to temperatures of between $71{ }^{\circ} \mathrm{C}$ and $149{ }^{\circ} \mathrm{C}$, the residual strength of the material was increased significantly when compared to the 28 day strength. This was explained as being the product of enhanced hydration. At temperatures of 177 ${ }^{\circ} \mathrm{C}$ and $232{ }^{\circ} \mathrm{C}$ however, a reduction of as much as $53 \%$ of the 28 day strength was recorded. This was thought to be as a result of the transformation of tobermorite gel to $\alpha$-dicalcium silicates which are poorly binding.

\footnotetext{
a e-mail: RCStein1@sheffield.ac.uk
}

This is an Open Access article distributed under the terms of the Creative Commons Attribution License 2.0, which permits unrestricted use, distribution, and reproduction in any medium, provided the original work is properly cited. 
$\mathrm{Xu}$ et al [3] reported beneficial changes in the residual strength of OPC-PFA concrete up to $250{ }^{\circ} \mathrm{C}$. Concurrent tests carried out on cement paste specimens indicated that this increase occurred simultaneously with a coarsening of the pore structure and an increase in total porosity as measured by mercury intrusion porosimetry (MIP). Grainger [4] also found that elevated temperatures of up to $300{ }^{\circ} \mathrm{C}$ proved beneficial for the strength of OPC-PFA pastes.

These findings contrast with those of Ghosh and Nasser [5] who reported a gradual decrease in the residual strength of OPC-PFA concrete after heating to temperatures between $21{ }^{\circ} \mathrm{C}$ and $232{ }^{\circ} \mathrm{C}$. Microstructural analysis of these specimens using scanning electron microscopy revealed a chemical transformation in the highly adhesive CSH gel, yielding a loose calcium silicate hydrate of different composition and poor cementing qualities. Chan et al [6] also recorded a steady decrease in the strength of OPC-PFA concrete for temperatures up to $400{ }^{\circ} \mathrm{C}$. MIP was used to characterise the pore structure of hardened cement paste pellets taken from the concrete and a coarsening of pore sizes was again recorded.

The effects of elevated temperature on the microstructure and in particular the pore structure of concrete therefore appear to be important in governing material strength and durability. However, measurement of pore characteristics is complicated due to the range of length scales over which they are observed. MIP is often used to characterise the pore structure of cement based materials down to pores of the order of a few nanometres. This technique however, systematically misallocates pore sizes as a result of the "accessibility effect" where the intrusion of smaller pores which lie before larger pores on the intrusion path of the mercury masks the presence of the larger pores because the intrusion pressure for these pores has already been overcome [7,8]. This effect is particularly noticeable with air voids above $10 \mu \mathrm{m}$ in diameter, which are often unreported in MIP studies despite constituting a significant proportion of the total porosity of cementitious materials. The quantitative analysis of concrete is also restricted due to the small specimen sizes required.

In this paper, non-destructive 3D X-ray Computed Tomography (XCT) imaging was carried out to characterise the air void structure of AGR concrete specimens conditioned at $105{ }^{\circ} \mathrm{C}$ and 250 ${ }^{\circ} \mathrm{C}$. The effect of air void pore structure on changes in residual strength is also reported.

\section{Materials and Experimental Method}

\subsection{Specimen preparation and conditioning}

One concrete type with a mix typical of that used to construct AGR pressure vessels was considered with all constituents and mass proportions shown in Table 1. Specimens were prepared in 2003 as part of an experimental programme investigating the strength of AGR pressure vessels [1]. The concrete was cast in slabs with dimensions of $740 \times 620 \times 150 \mathrm{~mm}$ and immersed in a temperature controlled water tank with a 10 day temperature matched curing cycle in which the temperature reached a maximum of $65{ }^{\circ} \mathrm{C}$. Following the 10 day cycle, the slabs were de-moulded and returned to the water tank for a further 60 days at $20{ }^{\circ} \mathrm{C}$. Each concrete slab was then cut and ground to form the $100 \mathrm{~mm}$ cubes used here. The machined cubes were stored at normal room temperature until conditioning with the unique $\operatorname{mac}^{2 \mathrm{~T}}$ apparatus for multi-axial compression of concrete at elevated temperature (Figure 1).

Table 1. Concrete mix proportions $(\mathrm{OPC}=$ Ordinary Portland cement; $\mathrm{PFA}=$ Pulverised fuel ash $)$

\begin{tabular}{|c|c|c|c|c|c|c|c|}
\hline Constituent Name & OPC & PFA & Sand & $\begin{array}{c}\text { Quartz- } \\
\text { diorite } 10 \\
\mathrm{~mm}\end{array}$ & $\begin{array}{c}\text { Quartz- } \\
\text { diorite 20 } \\
\mathrm{mm}\end{array}$ & $\begin{array}{c}\text { Plasticiser } \\
\text { SP4 }\end{array}$ & Water \\
\hline Cement Mass Ratio & 1 & 0.33 & 2.45 & 1.39 & 2.78 & 0.0006 & 0.56 \\
\hline
\end{tabular}

The experimental programme consisted of the six tests, with three individual conditioning regimes and two repeats each (Table 2). The conditioning regimes included (i) thermal treatment to 
$105^{\circ} \mathrm{C}$, (ii) thermal treatment to $250{ }^{\circ} \mathrm{C}$, and (iii) untreated control specimens. A heating/cooling rate of $0.2^{\circ} \mathrm{C} / \mathrm{min}$ was employed, with the peak temperature kept steady for a period of 24 hours before cooling. Following the conditioning treatments, a $28 \mathrm{~mm}$ diameter core was extracted from the centre of each cube for analysis using X-ray CT (Figure 2).

Table 2. Conditioning regimes of the concrete cubes for XCT analysis

\begin{tabular}{|c|c|c|c|}
\hline Conditioning Name & (i) $\mathrm{H} 105$ & (ii) $\mathrm{H} 250$ & (iii) Control \\
\hline Thermal Treatment & $105{ }^{\circ} \mathrm{C}$ & $250{ }^{\circ} \mathrm{C}$ & - \\
\hline
\end{tabular}
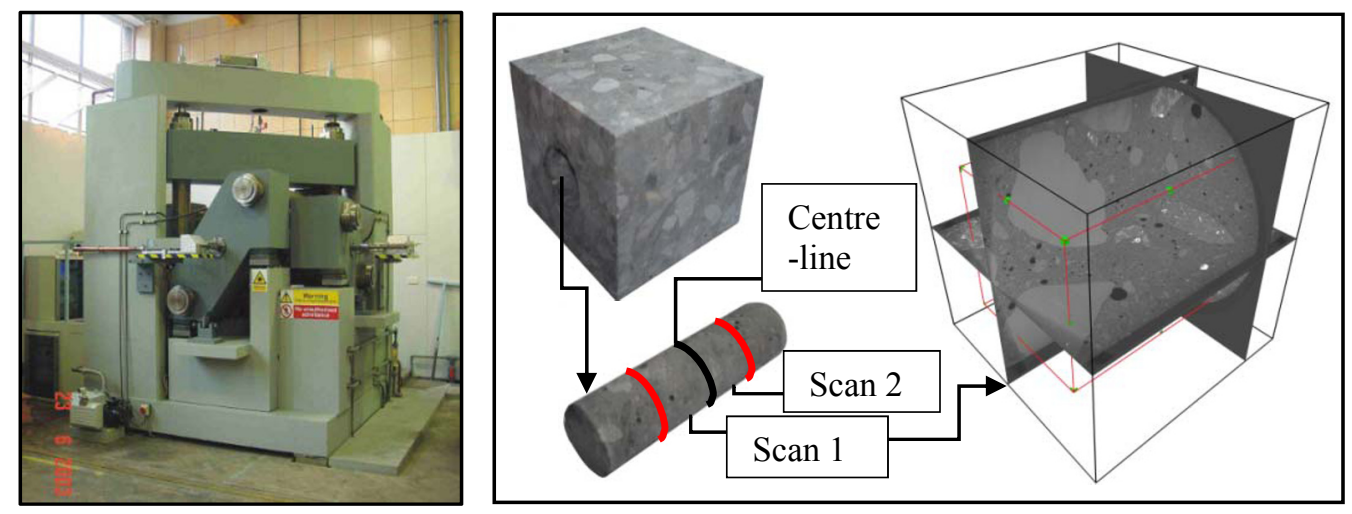

Fig. 1. (Left) Mac2T apparatus for multi-axial compression of concrete at elevated temperature.

Fig. 2. (Right) The $28 \mathrm{~mm}$ cylindrical core extracted from the conditioned specimen cube showing the two XCT scan regions and reconstructed XCT data for one scan $(29$ × 29 × $29 \mathrm{~mm})$ showing three orthogonal slices (orthoslices) of 3D pixels (voxels) [9]

\subsection{X-ray CT imaging and data processing}

X-ray CT analysis was carried out using the Nikon 225/320 kV Custom Bay at the MXIF, University of Manchester. The $225 \mathrm{kV}$ static anode with a tungsten target (3 $\mu \mathrm{m}$ spot size) was used in conjunction with a $1.5 \mathrm{~mm}$ thick copper filter in order to optimise the emitted x-ray beam energy spectrum. An accelerating voltage of $160 \mathrm{kV}$ and a current of $200 \mu \mathrm{A}$ were selected to achieve good attenuation contrast. Two scans were then taken of each specimen; one above and one below the centre line (Figure 2), resulting in 4 data sets for each conditioning regime. The source to specimen distance was $73.5 \mathrm{~mm}$, the source to detector distance was $1007 \mathrm{~mm}$ and the acquisition time per radiograph was $1000 \mathrm{~ms} .3142$ radiographs were taken through a rotation of $360^{\circ}$ during each tomographic scan and a voxel size of $14.6 \mu \mathrm{m}$ was achieved.

Image analysis was performed using the Avizo Fire software package. A cylindrical Region Of Interest (ROI) was selected from each scan with $28 \mathrm{~mm}$ diameter and $21 \mathrm{~mm}$ height to remove the effects of the cone shaped x-ray beam at the top and bottom of the data set. A 3D median filter and an anisotropic diffusion filter were applied in order to reduce image noise in each dataset. Minima thresholding was then used to differentiate air void porosity from cementitious and aggregate phases within the concrete. The Nyquist-Shannon sampling theorem [10] was used to determine the minimum size of features that could be resolved based on the image resolution of $14.6 \mu \mathrm{m}$. In this case, three voxels were chosen as the feature resolution limit meaning the smallest detectable air void in this study has a diameter of $31.5 \mu \mathrm{m}$. Equivalent air void diameters are calculated by assuming that all air voids are of a spherical geometry. A MATLAB routine was developed to calculate the relationship between each air void and its nearest neighbour using centroid data extracted from Avizo Fire. Experimental error for all results is shown in the form of standard deviation with respect to the mean. 


\subsection{Compression testing}

Uniaxial compression testing to specimen failure was carried out on the remaining cored cubes (Figure 2) using a Controls Automax 5 hydraulic compression rig with a constant load rate of 0.25 $\mathrm{MPa} / \mathrm{s}$.

\section{Results and Analysis}

\subsection{Pore structure analysis}

A typical reconstructed data set from the ROI of a control specimen is visualised using 3 orthoslices in Figure 3 along with the segmented air void structure in Figure 4. The orthoslices show the clear presence of large aggregate particles, cementitious matrix and air voids. Both igneous and sedimentary rock forms are present which is indicative of the Whinstone aggregate source used as aggregate in this experiment.
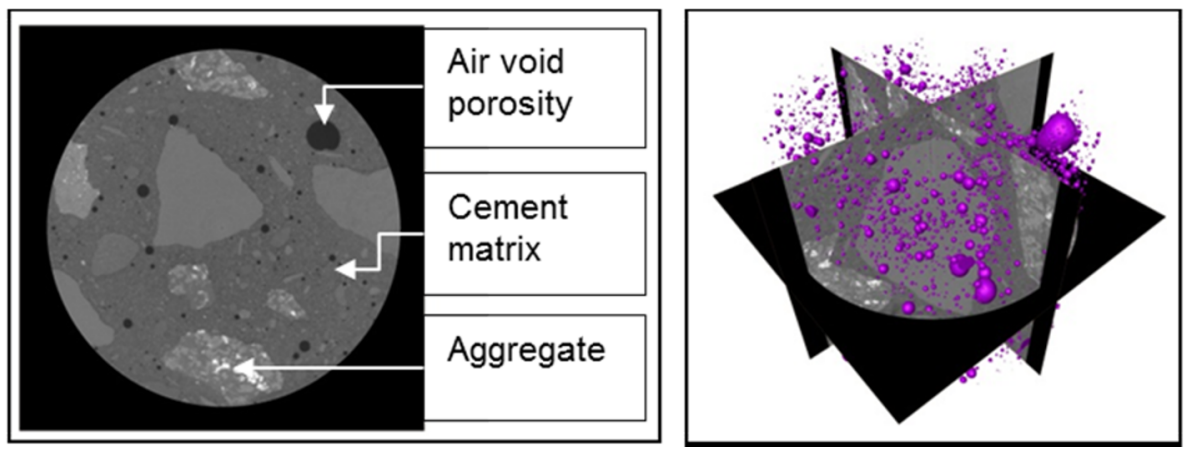

Fig. 3. (Left) Labelled ortho-slice showing filtered unconditioned dataset.

Fig. 4. (Right) Segmented air void structure overlayed on three orthogonal ortho-slices for filtered unconditioned dataset.

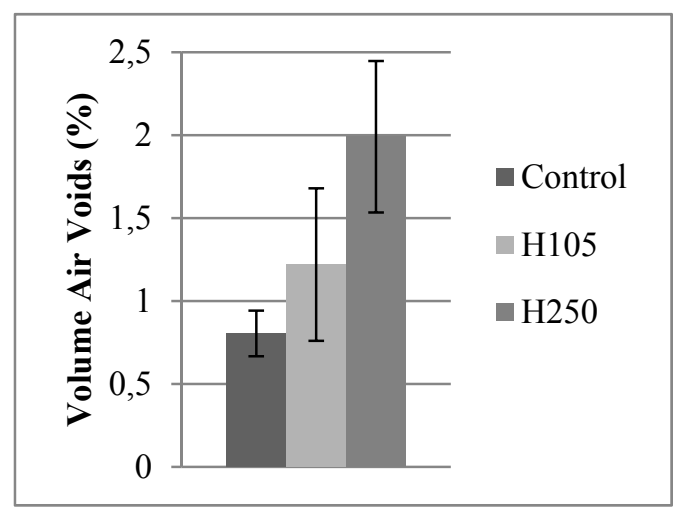

Fig. 5. Total air void volume for the three conditioning regimes.

Figure 5 shows the total air void porosity for each conditioning regime of voids larger than 31.5 $\mu \mathrm{m}$. A significant increase in volume is visible for specimens conditioned at $250{ }^{\circ} \mathrm{C}$ over unconditioned specimens. It also appears that the specimens conditioned at $105^{\circ} \mathrm{C}$ are subject to an increase in air void volume. However, further testing is required to better understand possible variations in these measurements and their effects on the error. The air void size distributions for the 
three conditioning regimes are shown in Figure 6. A general trend can be observed showing the coarsening of air voids in heated specimens above $150 \mu \mathrm{m}$ in diameter. This occurs simultaneously with a reduction in the frequency of air voids at $100 \mu \mathrm{m}$ and below with respect to both the control and $105{ }^{\circ} \mathrm{C}$ conditioned specimens. Air void size distributions for the control and $\mathrm{H} 250$ conditioned specimens show the same trend as those in the results presented in Stein et al [9]. However, individual values differ due to the application of the 3D median and anisotropic diffusion filters in this case which reduce image noise.

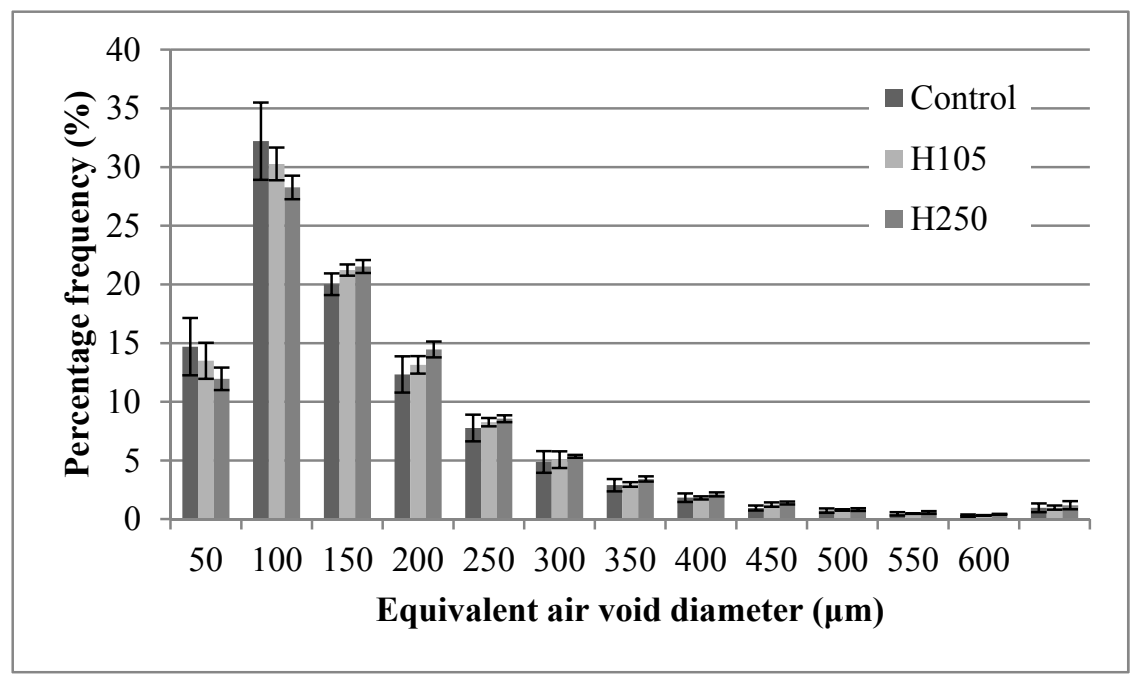

Fig. 6. Air void pore size distribution results for the three conditioning regimes.

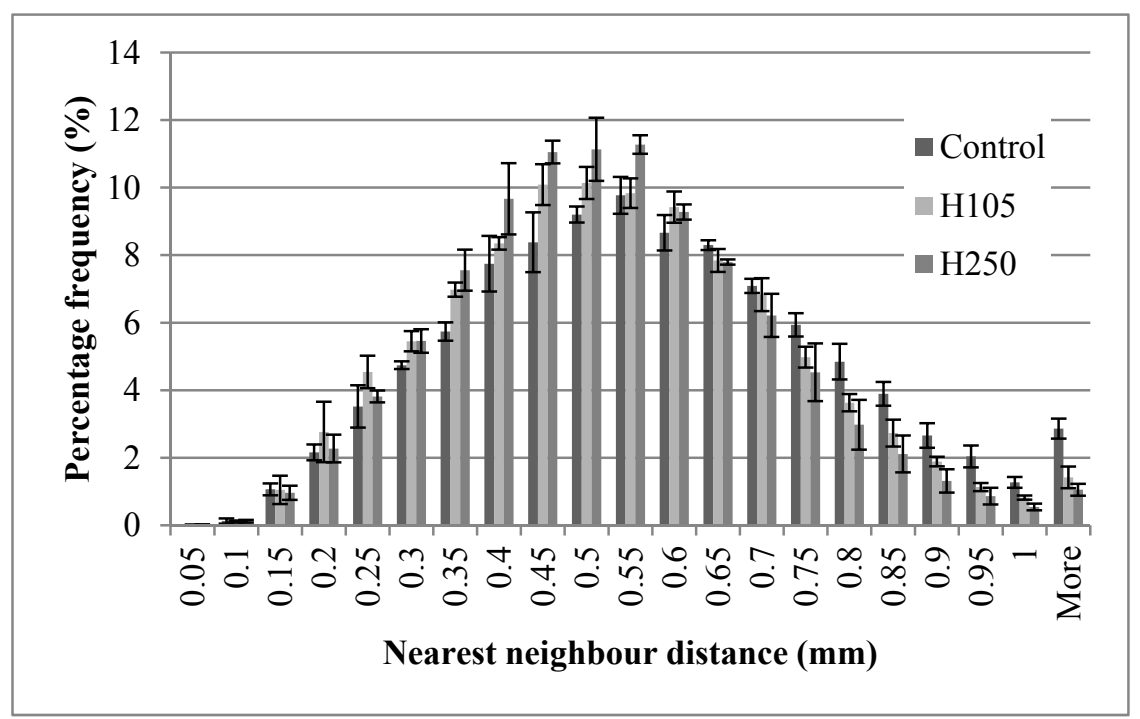

Fig. 7. Nearest neighbour distribution of air voids for the three conditioning regimes.

Figure 7 shows the relationship between discrete air voids in the form of distances measured between each air void and its closest neighbour. Specimens which have experienced thermal load are seen to contain air voids, which lie closer together than those which are unconditioned. For nearest neighbour distances of up to $0.6 \mathrm{~mm}$, the frequency of air voids in thermally loaded specimens is 
greater than that of the unconditioned control. Interestingly, in most cases this effect appears to occur incrementally where specimens conditioned to $250{ }^{\circ} \mathrm{C}$ have a greater frequency of air voids lying close together than those conditioned at $105{ }^{\circ} \mathrm{C}$. Beyond $0.6 \mathrm{~mm}$ however, the control specimens have a greater frequency of air voids. This is particularly evident in the $>1 \mathrm{~mm}$ category where the unconditioned control specimens have almost one order of magnitude more air voids than either of the thermally loaded conditioning regimes.

\subsection{Compression testing}

The compressive strengths of specimens in each of the three conditioning regimes are shown in Figure 8. A significant reduction in strength is recorded for the two thermally loaded regimes over the unconditioned control. The change in strength is most notable for specimens conditioned at 105 ${ }^{\circ} \mathrm{C}$ indicating that the phase change of water may play a significant role in strength reduction.

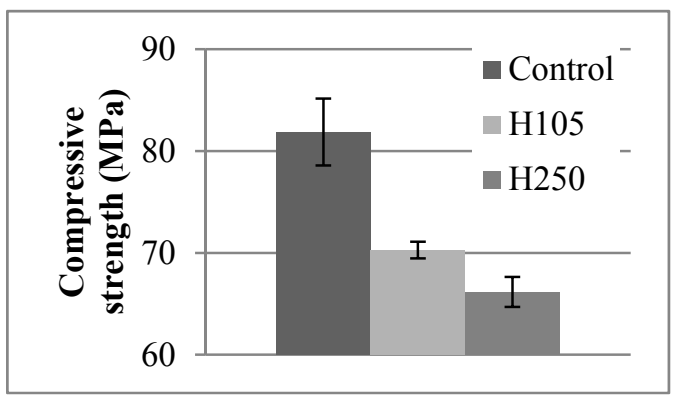

Fig. 8. Compressive strengths from specimens in each conditioning regime.

\section{Discussion}

An increase in the porosity of thermally loaded specimens and a coarsening of air void sizes has been observed, that is in line with the results presented in earlier research $[3,6]$. A concurrent decrease in material strength has also been observed up to $250{ }^{\circ} \mathrm{C}$ with the most significant decline occurring at $105{ }^{\circ} \mathrm{C}$. This contradicts the work of Xu et al. [3] who reported an increase in strength over this temperature range. It also differs from the work of Chan et al. [6], who observed a steady reduction in strength up to $400{ }^{\circ} \mathrm{C}$. One explanation for this is the boundary conditions imposed on the specimens in each experiment. Both Xu et al. [3] and Chan et al. [6] heated specimens inside a furnace with open boundary conditions. In this study, the mac ${ }^{2 \mathrm{~T}}$ apparatus was used to apply thermal load. Due to the design of the loading plattens, $90 \%$ of the specimen surface is effectively sealed. This would prevent the free movement of water away from the specimen and may explain the significant strength reduction for specimens conditioned at $105^{\circ} \mathrm{C}$.

The results presented here showing the relationship between air void nearest neighbours provides further insight into the reasons behind strength reduction. These measurements indicate a reduction in the average distance between air voids for thermally conditioned specimens. This reduction may reduce material strength through the promotion of crack propagation in the air void structure. Further in-situ compression testing of conditioned and unconditioned samples will provide insight whether the observed differences of air void nearest neighbours play a significant role in specimen failure.

Observed differences of the strength of thermally loaded specimens appear to have greater significance compared to changes of total air void porosity and air void size distribution, particularly for the specimens conditioned at $105{ }^{\circ} \mathrm{C}$. One explanation for this is that the air void structure results do not take into account alterations in the capillary and gel pore structures. This implies that changes in the air void pore structure are only partially responsible for the reduction in ultimate strength of 
the material and further analysis at higher image resolutions would yield further pore structure changes that also had an impact on material strength.

\section{Conclusions}

- OPC-PFA concrete heated in partially sealed conditions experiences a significant reduction in compressive strength.

- Thermal treatment results in an increase in air void porosity accompanied both by a coarsening of the air void structure and a decrease in the nearest neighbour distance of individual air voids.

- These changes are believed to be only partially responsible for the reduction in failure strength of the material.

In-situ tomography will be carried out on cement paste and concrete specimens at higher feature resolutions to gain a greater understanding of the relationship between pore structure and strength of thermally loaded OPC-PFA materials. The results of this and future studies are exceptionally useful for the development and calibration of numerical models.

\section{Acknowledgements}

RS is funded with an EPSRC studentship through the Nuclear FiRST DTC grant EP/G037140/1. Funding is also acknowledged from the EPSRC for the MXIF under EP/I02249X, EP/F007906/1 and $\mathrm{EP} / \mathrm{F} 028431 / 1$.

\section{References}

1. M. Petkovski and R. Crouch, Cem. Con. Res., 38, 586-596 (2008)

2. K. Nasser and H. Marzouk, J. Am. Concr. Inst., 76, 537-550 (1979)

3. Y. Xu, Y. L. Wong, C. S. Poon, and M. Anson, Cem. Con. Res., 31, 1065-1073 (2001)

4. B. N. Grainger, Central Electricity Research Laboratories, UK (1980)

5. S. Ghosh and K. Nasser, ACI Materials Journal, 93, 51-60 (1996)

6. Y. N. Chan, G. F. Peng, and M. Anson, Cem.Con. Comp., 21, $23-27$ (1999)

7. $\quad$ S. Diamond, Cem. Con. Res., 30, 1517-1525 (2000)

8. J. Kaufmann, J. Am. Ceram. Soc., 92, 209-216 (2009)

9. R. C. Stein, M. Petkovski, D. L. Engelberg, N. C. Hyatt, T. Lowe, and P. J. Withers, in 2nd International conference on microstructure related durability of cementitious composites (2012)

10. A. Jerri, Proceedings of the IEEE, 65, 1565-1595 (1977) 